\title{
Molecular order of air-stable p-type Organic Thin-Film Transistors by tuning the extension of the $\pi$-conjugated core: the cases of Indolo[3,2- $b$ ]carbazole and Triindole semiconductors
}

\author{
Marta Reig, ${ }^{a}$ Joaquim Puigdollers ${ }^{b}$ and Dolores Velasco $*^{a}$ \\ ${ }_{5}$ Received 31 Jul 2014, Accepted 01 Oct 2014, First published online 07 Oct 2014
}

\section{DOI: 10.1039/ C4TC01692K}

Charge transport in organic devices depends strongly on the molecular order and morphology of the organic semiconductor thin films. In the design of new organic semiconductors, the selection of the appropriate core plays a key role in the molecular packing and charge transport characteristics of the 10 organic device. Four derivatives of carbazole that mainly differ in the extension of the $\pi$-conjugated core, including indolo[3,2-b]carbazole and triindole derivatives, exhibited hole mobilities ranging from $10^{-5}$ to $10^{-2} \mathrm{~cm}^{2} \mathrm{~V}^{-1} \mathrm{~s}^{-1}$ as active layers in Organic Thin-Film Transistors (OTFTs). X-ray analysis of single crystals and evaporated thin films gave insights into the molecular packing of the compounds that justified their OTFTs characteristics.

\section{Introduction}

After intensive research efforts, p-type OTFTs have now successfully achieved hole mobilities comparable to those obtained with amorphous silicon. The performances of OTFTs 20 have experienced an impressive progress in recent years, due to the processing of new materials, device geometries and morphology control. However, the properties of the organic semiconductors still determine the performance of OTFT devices. In view of this, when designing new suitable organic compounds ${ }_{25}$ for molecular electronics, the selection of an appropriate core structure is a significant aspect to take into account, ${ }^{1}$ because it could modulate the optical and electronic properties and even determine the stability and durability of the fabricated devices under ambient conditions. One strategy to achieve materials with 30 high air stability is to work with compounds that exhibit lowlying high occupied molecular orbital (HOMO) levels, in order to obtain compounds stable against oxidative doping by atmospheric oxygen.

The search of high mobility organic semiconductors has 35 yielded pentacene as one of the most promising materials, achieving high hole mobilities of $3 \mathrm{~cm}^{2} \mathrm{~V}^{-1} \mathrm{~s}^{-1}$ for vacuum deposited OTFTs. ${ }^{1 \mathrm{~b}, 2}$ Nevertheless, pentacene-based devices present several drawbacks for practical applications due to a lack of air stability and fast device degradation. ${ }^{3}$

40 Carbazole derivatives have been widely studied as holetransporting semiconductors, due to its electron-donating capabilities. ${ }^{4}$ In addition, they are recognised as reasonably stable compounds against oxidative doping by atmospheric oxygen. The carbazole unit presents a series of advantages ahead of other 45 conventional organic semiconductors, such as its low cost, easy availability, and its high stability in environmental conditions.

In this work we deal with the study of 9-methyl-9H-carbazole 1, 9,9'-dimethyl-9H,9H'-[3,3']bicarbazole 2, 5,11-dimethylindolo[3,2-b]carbazole 3, and $N$-trimethyltriindole 4 (Fig. 1) as 50 active organic semiconductor layers in OTFTs. Within this series, the extension of the $\pi$-conjugated core was progressively varied, leading to improved OTFTs performances of $10^{-2} \mathrm{~cm}^{2} \mathrm{~V}^{-1} \mathrm{~s}^{-1}$.

Indolo[3,2-b]carbazole and triindole show extended $\pi$ systems, in which two or three carbazole units, respectively, share an 55 aromatic ring. Indolo[3,2-b]carbazole and triindole unit present a planar structure with two or three N-H units, respectively, which allows easy introduction of alkyl chains, in order to increase the solubility of the systems and to promote the molecular order of the materials during the deposition process. Both heterocycles 60 display large energy band gaps and low-lying HOMO energy

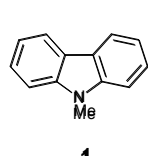

65
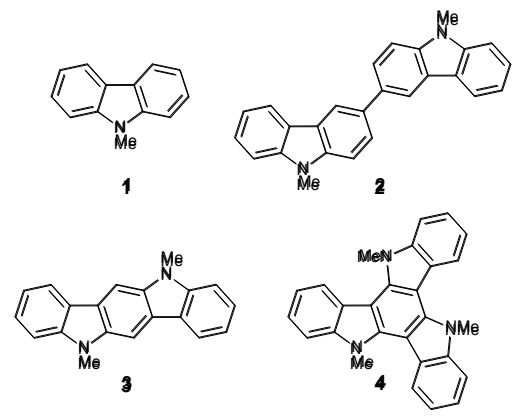

Fig. 1 Molecular structure of carbazole based derivatives 1-4.

70 levels. In the last years, indolocarbazole has received special attention as a building block in the field of organic electronics, and recent studies have shown the great potential of indolo[3,2- 
b] carbazole-based derivatives to be used in OTFTs. ${ }^{5}$ The triindole core presents a larger molecular structure than the indolocarbazole one. Accordingly, a higher molecular order could be expected from it and therefore, better charge carrier transport. ${ }_{5}$ To the best of our knowledge, there are still no studies about the application of triindole derivatives in OTFTs. Recently, triindole derivatives have been described as suitable organic materials in Organic Solar Cells (OSCs) ${ }^{6}$ and OLEDs. ${ }^{7}$ The charge transport properties of liquid crystal-based triindole derivatives ${ }^{8}$ and of 10 triindole $\mathbf{4}$ have been reported by the space-charge-limitedcurrent method (SCLC), yielding values of hole mobilities for the later ranging from $\sim 1 \times 10^{-4}$ to $\sim 1 \times 10^{-3} \mathrm{~cm}^{2} \mathrm{~V}^{-1} \mathrm{~s}^{-1}$. ${ }^{6}$ The easy preparation, high thermal stability, $\pi$-stacking capability, high carrier mobilities, and optoelectronic properties of such 15 molecules make indolocarbazole and triindole-based materials very promising organic semiconductors for optoelectronic applications.

Here, we report not only the OTFT performance of carbazole containing compounds $\mathbf{1 - 4}$, but also the determination of the 20 molecular packing in the organic semiconductor layer of the devices by means of X-ray diffraction (XRD) studies. Therefore, the aim of this work is to determine the correlation of the device performance with the molecular order in the semiconducting thin films in function of the $\pi$-conjugated core design of the organic 25 semiconductors.

\section{Results and discussion}

\section{Synthesis and physical properties}

Compound 2 was synthesized by oxidative dimerization of 9methyl-9H-carbazole with $\mathrm{FeCl}_{3}$ in anhydrous chloroform 30 following a preaviously reported procedure. ${ }^{9}$ Indolo[3,2$b]$ carbazole was synthesized by condensation of 1,4cyclohexanodione with phenylhydrazine, followed by a double Fischer indolization. ${ }^{10}$ Triazatruxene was synthesized by the cyclocondensation of 2-oxindole. ${ }^{11} N$-methyl derivatives $\mathbf{1}, \mathbf{3}$ and ${ }_{35} \mathbf{4}$ of the corresponding $9 H$-carbazole, indolo[3,2-b]carbazole, and triazatruxene were obtained by methylation under standard conditions in high yields. Compounds 1-4 were enterely characterized by ${ }^{1} \mathrm{H}-\mathrm{NMR},{ }^{13} \mathrm{C}-\mathrm{NMR}$ and MS.

Indolocarbazole $\mathbf{3}$ and triindole $\mathbf{4}$ exhibited high thermal 40 stability by thermal gravimetric analysis (TGA), showing the onset of decomposition at $384{ }^{\circ} \mathrm{C}$ and $461{ }^{\circ} \mathrm{C}$, respectively.

Compounds 1-4 showed one oxidation process by cyclic voltammetry, whereas no reduction processes were observed for
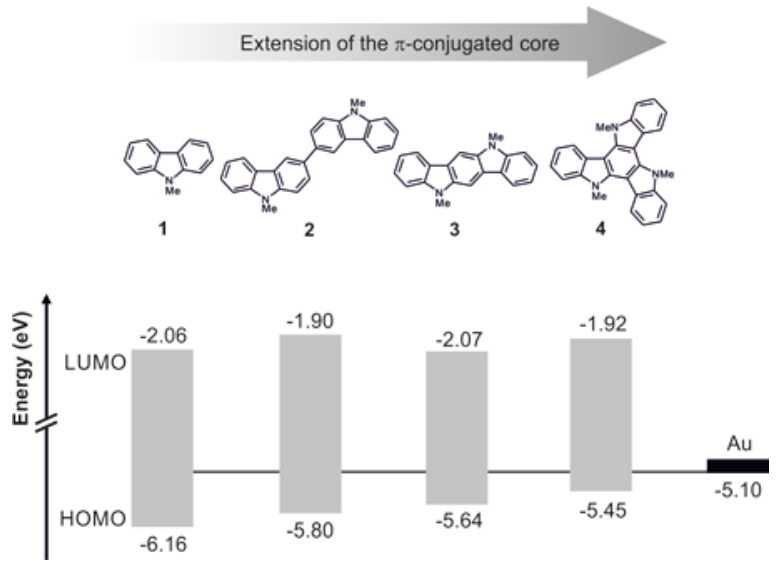

${ }_{45}$ Fig. 2 Energy levels (HOMO-LUMO) of materials 1-4 measured by cyclic voltammetry. Gold is also shown for comparison.

any of them. Table 1 collects the electrochemical characteristics, the HOMO energy level estimated from cyclic voltammetry and 50 the energy band gap estimated from the UV-visible spectra (the absorption spectra and cyclic voltammograms can be found in the ESI, Fig. S1-S2 $\dagger$ ). In this series of carbazole-based compounds, when increasing the conjugation of the system, the HOMO levels are slightly destabilized from $-6.16 \mathrm{eV}$ for carbazole $\mathbf{1}$ to -5.45 $55 \mathrm{eV}$ corresponding to triindole derivative 4 (Fig. 2). The relative low-lying HOMO levels and high HOMO-LUMO gaps $(\sim 3.7 \mathrm{eV})$ of these compounds are indicative of their potential hole transporting properties. Moreover, the energy levels found for the organic semiconductors 1-4 are perfectly suitable to Au electrode 60 work function $(-5.1 \mathrm{eV})$ as it is displayed in Fig. 2.

\section{Organic Thin-Film Transistors}

Charge carrier mobilities were measured by using the organic materials 1-4 as vacuum-deposited active layers in standard 65 bottom gate-top contact OTFTs.

Fabrication of OTFTs with compound $\mathbf{1}$ as the organic semiconductor layer was not successful, due to its low sublimation temperature $\left(40^{\circ} \mathrm{C}\right.$ at $10^{-6}$ mbar under the experimental conditions during the deposition process). 2-based 70 devices fabricated with $50 \mathrm{~nm}$ thick $\mathrm{SiO}_{2}$ dielectric presented a bad yield and reproducibility: only $17 \%$ of the devices fabricated with polystyrene (PS) treated substrates presented OTFT characteristics, with a maximum hole mobility around $2 \times 10^{-5}$ $\mathrm{cm}^{2} \mathrm{~V}^{-1} \mathrm{~s}^{-1}$ and a threshold voltage of $-16.0 \mathrm{~V}$ (Table 1).

75 Table 1 Optical and electrochemical properties for compounds 1-4 and OTFT characteristics of devices based on 1-4 carbazole derivatives with polystyrene treated c-Si/ $\mathrm{SiO}_{2}$ substrates.

\begin{tabular}{clcccccc}
\hline compound & \multicolumn{1}{c}{$\lambda_{\text {abs }}(\varepsilon)^{\mathrm{a}} \mathrm{nm}\left(\mathrm{M}^{-1} \mathrm{~cm}^{-1}\right)$} & $E^{\text {ox }}{ }_{\text {nnset }}{ }^{\mathrm{b}}(\mathrm{V})$ & $E_{\text {gap }}{ }^{\mathrm{c}}(\mathrm{eV})$ & $E_{\mathrm{HOMO}} / E_{\mathrm{LUMO}}(\mathrm{eV})$ & $\mu\left(\mathrm{cm}^{2} \mathrm{~V}^{-1} \mathrm{~s}^{-1}\right)$ & $\mathrm{V}_{\text {th }}(\mathrm{V})$ & $\mathrm{I}_{\text {on }} / \mathrm{I}_{\text {off }}(\mathrm{A} / \mathrm{A})$ \\
\hline $\mathbf{1}$ & $263(32314), 294(29722)$ & 1.20 & 4.10 & $-6.16 /-2.06$ & - & - & - \\
$\mathbf{2}$ & $303(76660)$ & 0.84 & 3.90 & $-5.80 /-1.90$ & $2 \times 10^{-5}$ & -16.0 & $\sim 10^{1}$ \\
$\mathbf{3}$ & $283(52268), 340(67146)$ & 0.68 & 3.57 & $-5.64 /-2.07$ & $7 \times 10^{-3}\left(1 \times 10^{-3}\right)^{\mathrm{e}}$ & $-9.6(-5.5)^{\mathrm{e}}$ & $\sim 10^{4}$ \\
$\mathbf{4}$ & $317(79023)$ & - & 3.53 & $-5.45^{\mathrm{d}} /-1.92$ & $3 \times 10^{-2}\left(1 \times 10^{-2}\right)^{\mathrm{f}}$ & $-12.8(-9.0)^{\mathrm{f}}$ & $\sim 10^{3}$
\end{tabular}

${ }^{a}$ Wavelength of the maximum absorption and molar extinction coefficient. ${ }^{\mathrm{b}}$ Onset oxidation potential. ${ }^{\mathrm{c}}$ Energy difference between HOMO and LUMO orbitals. ${ }^{\mathrm{d}}$ Determined from data given in ref. $6 \mathrm{~b} .{ }^{\mathrm{e}}$ Maximum value registered on the $8^{\text {th }}$ day. ${ }^{\mathrm{f}}$ Maximum value registered the $5^{\text {th }}$ day. The results in parentheses are for the measurements after five months in air. 


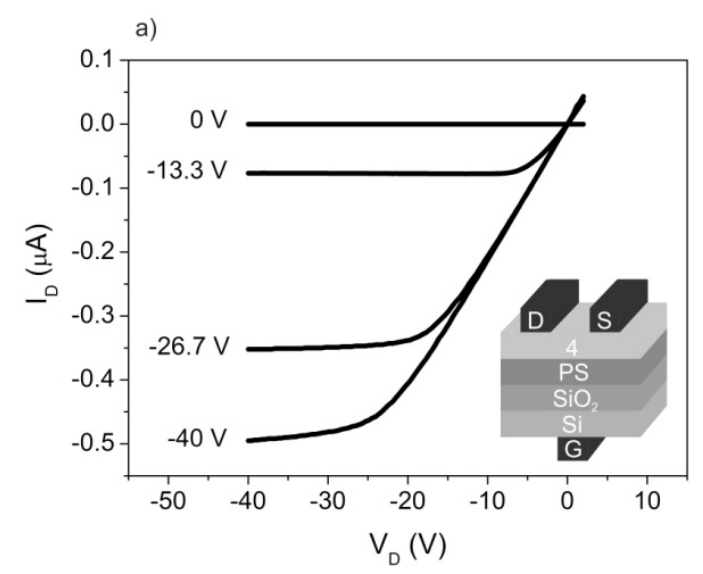

c)

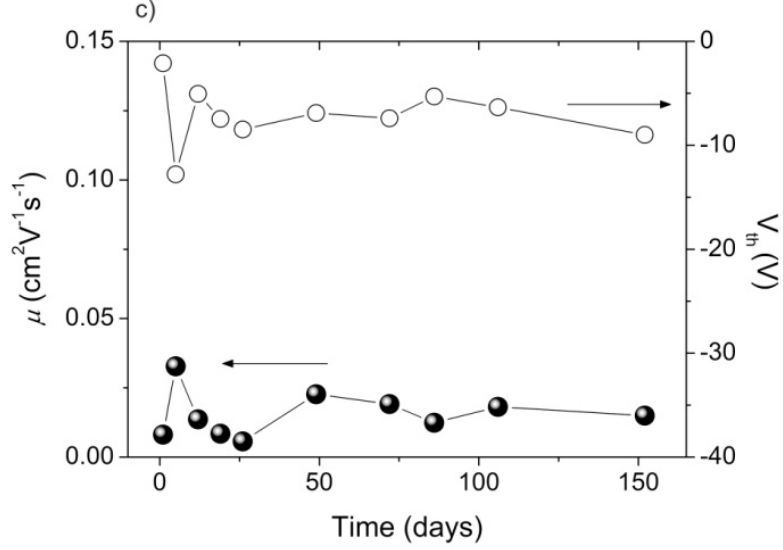

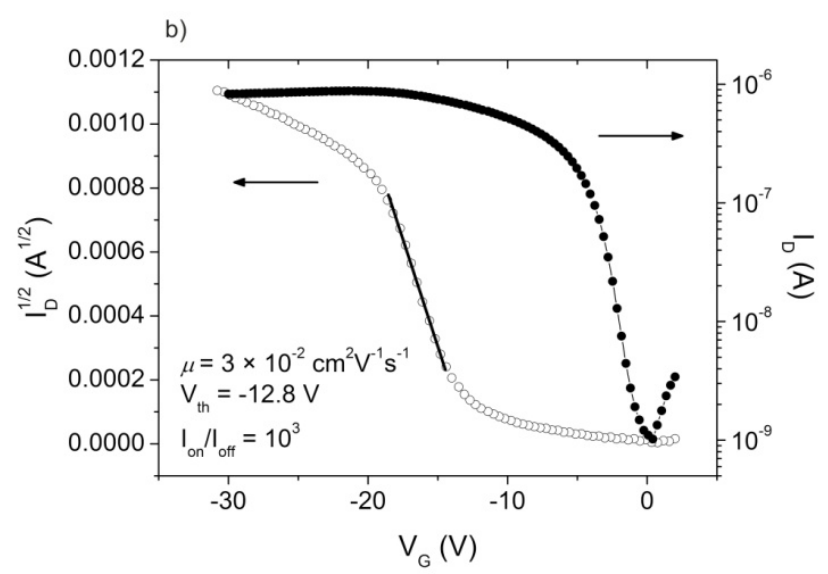

d)

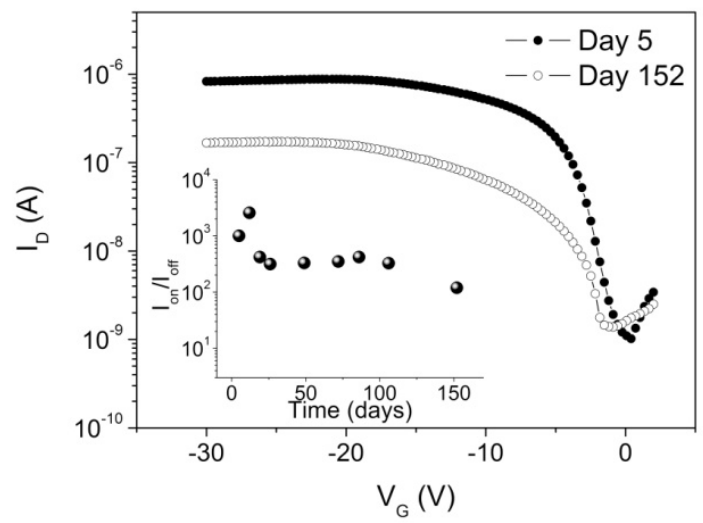

Fig. 3 OTFTs characteristics of a device fabricated with $\mathbf{4}$ as the semiconductor layer and with PS-treated substrate. a) Output characteristics at different gate voltages $\left(V_{G}\right)$. b) Transfer $\left(V_{D}=-20 \mathrm{~V}\right)$ and saturation characteristics. c) Mobility and threshold voltage of one representative device fabricated with $\mathbf{4}$ as the semiconductor layer and with PS-treated substrate as a function of storage time in 5 the air. d) Transfer characteristics for the $5^{\text {th }}$ day and the $152^{\text {nd }}$ day of the experiment at $V_{D}=-20 \mathrm{~V}$. Inset figure shows the evolution with time of the $\mathrm{I}_{\mathrm{on}} / \mathrm{I}_{\text {off }}$ ratio of the selected device.

Table 1 presents the device characterization for OTFTs fabricated with the more extended $\pi$-conjugated cores of 10 compounds 3 and $\mathbf{4}$. Devices fabricated with substrates of $50 \mathrm{~nm}$ of $\mathrm{SiO}_{2}$ presented similar hole mobilities, but lower threshold voltages, than those fabricated from substrates of $110 \mathrm{~nm}$ of $\mathrm{SiO}_{2}$. The reproducibility of the measurements and the yield of the working devices were found to be independent of the thickness of 15 the $\mathrm{SiO}_{2}$ layer. The highest values of charge mobilities were achieved by modifying the dielectric surface with a polystyrene thin film layer, which also resulted in lower threshold voltages and a higher reproducibility. 3 and 4 PS-treated $\mathrm{SiO}_{2}$ devices presented a superior yield given by the average of ten devices (3:

$2089 \%$ and 4: 100\%) exhibiting all of the tested devices similar performances. The highest hole mobility was registered for triindole $4,3 \times 10^{-2} \mathrm{~cm}^{2} \mathrm{~V}^{-1} \mathrm{~s}^{-1}$ in front of $7 \times 10^{-3} \mathrm{~cm}^{2} \mathrm{~V}^{-1} \mathrm{~s}^{-1}$ for the indolocarbazole 3 . The OTFTs characteristics of 3 - and 4based devices fabricated on bare $\mathrm{SiO}_{2}$ surfaces showed lower 25 reproducibility and lower charge mobilities of $7 \times 10^{-5}$ and $5 \times$ $10^{-3} \mathrm{~cm}^{2} \mathrm{~V}^{-1} \mathrm{~s}^{-1}$, respectively.

A representative output, transfer and saturation characteristics for 4-based OTFTs are shown in Fig. 3 (Fig. 3a and b; for OTFT characteristics of compound 3-based devices see ESI, Fig. S3a
30 and $\mathrm{b} \dagger$ ). The output characteristics are indicative of the OTFT behaviour of the device in both the linear and saturated regions. The hole mobility $(\mu)$ in the saturated region and the threshold voltage $\left(V_{\mathrm{th}}\right)$ were calculated from eqn (1):

$$
I_{D}=\frac{W C_{o x} \mu}{2 L}\left(V_{G}-V_{t h}\right)^{2}
$$

35

where $W$ and $L$ are the channel width and length, respectively, $C_{\mathrm{ox}}$ is the unit dimensional dielectric capacitance of gate insulator, $\mu$ is the hole mobility and $V_{\text {th }}$ is the threshold voltage.

A key requirement in the design of new semiconductors is the 40 stability under ambient conditions. OTFTs fabricated with both types of semiconductors $\mathbf{3}$ and $\mathbf{4}$ operate well in air, exhibiting remarkable ambient storage stability. Similar threshold voltages, mobilities and $I_{\mathrm{on}} / I_{\mathrm{off}}$ ratios were obtained after 5 months of storage in air and in dark conditions, demonstrating excellent air 45 stability (Fig. 3c and d, the air-stability experiments for 3-based devices can be found in the ESI, Fig. S3c and $\mathrm{d} \dagger$ ). The increase in charge mobilities after the first days of exposure to air can be attributed to p-doping of the device by $\mathrm{O}_{2}$. 
a)

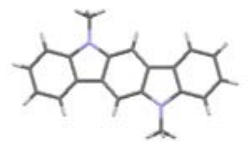

b)

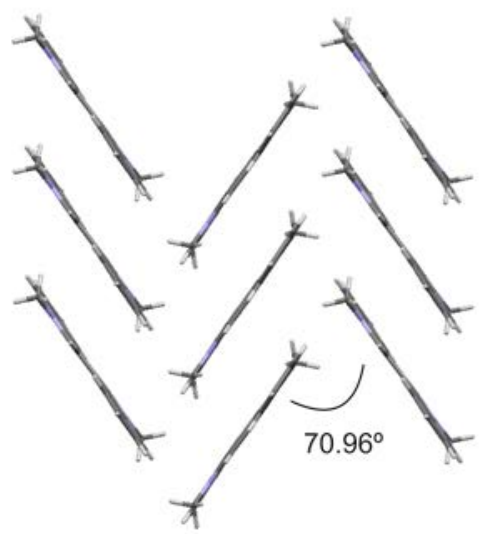

c)

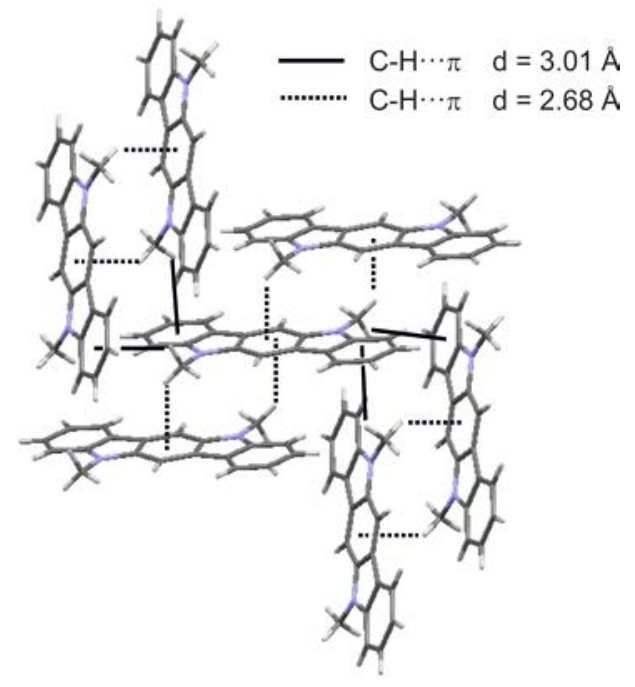

Fig. 4 Single crystal structure of compound 3. a) Molecular structure, b) herringbone packing motif with its corresponding herringbone angle and c) short contacts given by $\mathrm{C}-\mathrm{H} \cdots \pi$ interactions.

\section{Molecular order and morphology of the thin films}

For further exploration of the relationship between the OTFTs performance and the role of the molecular order in the thin films, grazing incidence X-ray diffraction (GIXRD) and atomic force microscopy (AFM) analysis were performed.

10 First of all, the knowledge of the single crystal structure of compounds $\mathbf{3}$ and $\mathbf{4}$ was crucial because it could provide the molecular packing motif and indicate the main intermolecular interactions of these compounds. The crystal structure of triindole derivative 4 was previously reported ${ }^{12}$ to adopt a face-to-face 15 packing in an alternate arrangement due to $\pi-\pi$ interactions between adjacent triindole molecules. For that compound, two different distances (3.53 $\AA$ and $3.68 \AA$ ) between two neighbouring molecules were observed due to the steric hindrance induced by the methyl groups.

20 In order to examine the molecular packing and the intermolecular interactions in the indolocarbazole derivative $\mathbf{3}$, the single crystal structure was determined by X-ray crystallography. The compound crystallizes in space group $\mathrm{C} 2 / \mathrm{c}$ of the monoclinic system with unit-cell dimensions of $a=$ 25 16.8377(13) $\AA, b=5.6889(4) \AA, c=15.3882(11) \AA, \beta=$ $106.671(2)^{\circ}$, and volume $=1412.05(18) \AA^{3}$. The cif file and the detailed crystallographic data are provided in the ESI (Table S1S5 and Fig. S4†).

The X-ray structure of $\mathbf{3}$ is shown in Figure 4. The molecular 30 structure of indolocarbazole $\mathbf{3}$ is nearly planar, with a small torsion angle around $1.5^{\circ}$ (Fig. 4a). The molecules exhibit a herringbone packing motif with a herringbone angle of $70.96^{\circ}$ (Fig. 4b). Every molecule is surrounded by six molecules showing $\mathrm{C}-\mathrm{H} \cdots \pi$ interactions between one of the hydrogen atoms 35 of the methyl groups with the central benzene ring of an adjacent indolocarbazole molecule with a distance of 2.68 A. Moreover, one of the hydrogen atoms of the methyl groups also interacts with one peripheral benzene ring with a distance of $3.01 \AA$, being responsible for the above-mentioned herringbone packing motif 40 (Fig. 4c).

For indolo[3,2-b]carbazole derivatives, the packing motif in the solid state strongly depends on the length of the alkyl chain in the nitrogen position of the indolocarbazole derivatives. Different packing motifs have been described in previously reported 45 methods, from the non-substituted indolo[3,2-b] carbazole $^{13}$ to alkylated derivatives. ${ }^{13,14} \quad$ For GIXRD studies, 75-nm thick films were deposited by sublimation in a vacuum system of compounds $\mathbf{3}$ and $\mathbf{4}$ on both bare and on polystyrene treated c$\mathrm{Si} / \mathrm{SiO}_{2}$ surfaces. All the thin films showed strong diffraction 50 peaks, which suggested that both $\mathbf{3}$ and $\mathbf{4}$ produced well-ordered films under the experimental conditions (Fig. 5). As shown in Fig. 5a, vacuum deposited 3 thin films on bare and on PS-treated $\mathrm{c}-\mathrm{Si} / \mathrm{SiO}_{2}$ surfaces presented identical X-ray diffraction patterns, which means that molecules are equally oriented, both on bare 55 and on PS-treated $\mathrm{SiO}_{2}$ surfaces. The combination of the GIXRD studies with the powder XRD data and the single crystal structures provides valuable information about the molecular order in the thin films. ${ }^{13,15}$

Thin films based on indolocarbazole 3 presented only one 60 strong diffraction peak in the GIXRD patterns at $2 \theta=11.1^{\circ}$, in comparison to the more complex diffractogram spectra obtained from the powder XRD data (Fig. S5a† in the ESI). From the single crystal data and the powder XRD pattern, the diffraction peak at $2 \theta=11.1^{\circ}$ can be undoubtedly assigned to the reflection 65 200. The XRD study shows that the plane (100) is parallel to the $\mathrm{c}-\mathrm{Si} / \mathrm{SiO}_{2}$ substrate, i.e. with $b$ - and $c$-axis also in the parallel plane. The molecular packing within the thin film corresponds to that of indolocarbazole $\mathbf{3}$ in the single crystal. This suggests that the molecules are tilted with an angle of $68^{\circ}$ to the substrate (Fig. $705 \mathrm{a}$ and $\mathrm{b}$ ).

For vacuum deposited 4 thin films on PS-treated substrates, one diffraction peak was mainly observed in the thin film XRD pattern at $2 \theta=8.3^{\circ}$, together with a second order diffraction peak 
at $2 \theta=16.6^{\circ}$, which is indicative of a higher crystalline thin film

than that obtained for indolocarbazole 3 . From the single crystal

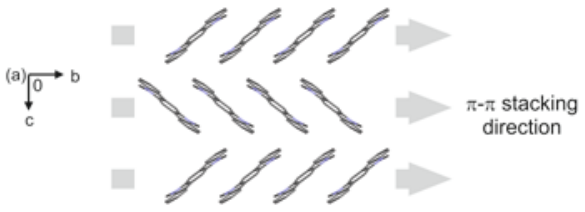

b)
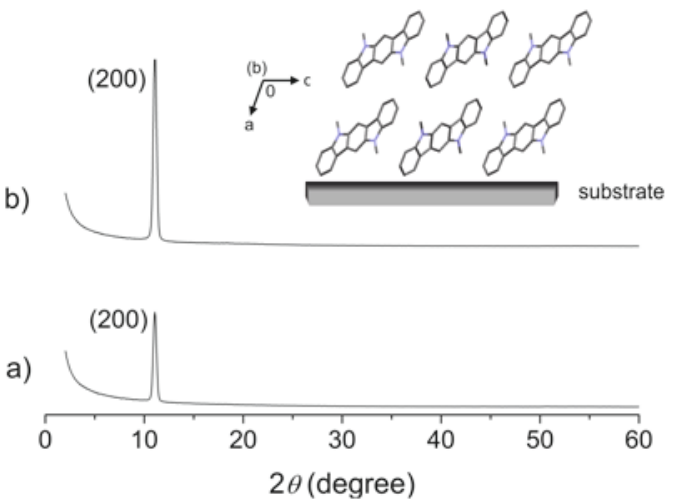
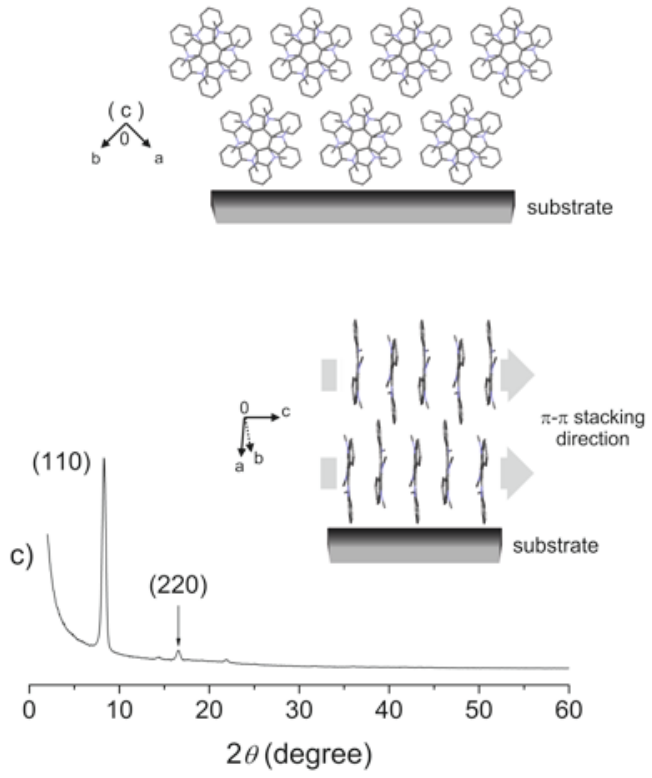

Fig. 5 GIXRD pattern of vacuum-deposited 3 films on a) bare and b) polystyrene-treated c-Si/SiO ${ }_{2}$ surfaces. The inset image shows the molecular packing of compound 3 with the (100) plane situated at $27^{\circ}$ (above) and perpendicular (below) to the paper plane, respectively. c) GIXRD pattern of vacuum-deposited 4 film on polystyrene treated c-Si/SiO ${ }_{2}$ surface. The inset images show the molecular packing in the thin films seen from two different perspectives, being the (110) plane situated perpendicular to the paper. The hydrogen atoms were 10 omitted for clarity.

data $^{12}$, the powder XRD pattern (Fig. S5b† in the ESI) and the GIXRD data, the diffraction peaks at $2 \theta=8.3^{\circ}$ and $2 \theta=16.6^{\circ}$ were assigned to the corresponding reflections 110 and 220, 15 respectively, suggesting that they are parallel to the substrate with the $c$-axis also in the parallel plane. Consequently, as it is collected in Fig. 5c, triindole molecules are located totally perpendicular $\left(90^{\circ}\right)$ to the substrate surface.

For the OTFTs performance, the best charge carrier mobility 20 was found for the triindole derivative 4-based devices in comparison with those obtained from the indolocarbazole 3 . This improvement in the charge carrier mobility value can be related to the different packing motifs and the corresponding different intermolecular interactions, and with the different molecular 25 order in the thin films. From the single crystal data reported above, it can be established that a change in the packing motif exists from the herringbone of compound 3 with $\mathrm{CH}_{3} \cdots \pi$ interactions to a face-to-face arrangement of compound $\mathbf{4}$ dominated by $\pi-\pi$ interactions, in which the electronic coupling is 30 maximized and the charge transport should be favoured. As a second important point, the GIXRD suggests that molecules in $\mathbf{4}$ are located completely perpendicular to the substrate, which seems to be the best molecular disposition for the charge transport through the semiconductor active layer of an OTFT 35 with a bottom-gate top-contact geometry.

In addition to the local intermolecular interactions, the film morphology and the grain sizes and boundaries strongly influence the charge transport properties, particularly at the interface between the semiconductor and the dielectric. AFM images were 40 taken from $\mathbf{3}$ and $\mathbf{4}$ films deposited by sublimation on both bare and polystyrene treated $\mathrm{SiO}_{2}$ surfaces (Fig. 6). Remarkable morphology differences were observed between them.

Thin films based on indolocarbazole 3 deposited on bare $\mathrm{SiO}_{2}$ and on PS-treated surfaces showed similar topography profiles. ${ }_{45}$ Both films present a similar average grain size, with an average

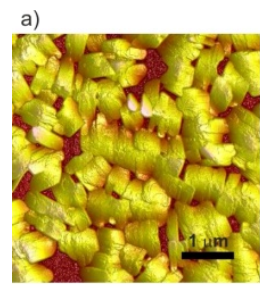

b)
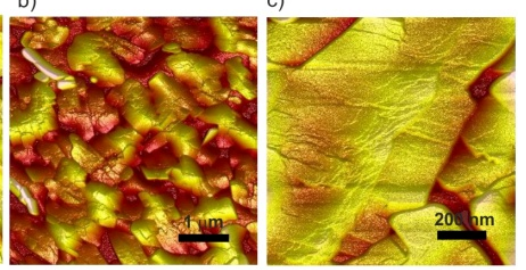

e)

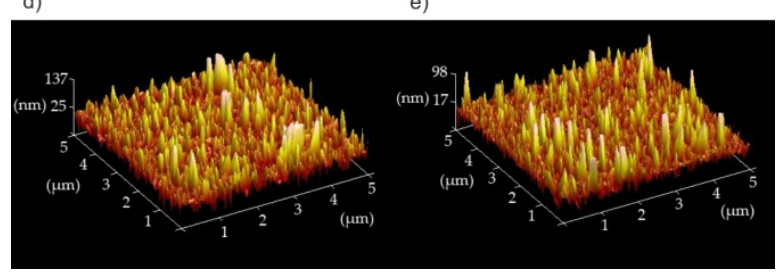

Fig. 6 AFM images of vacuum-deposited 3 films deposited on a) 50 bare $\mathrm{SiO}_{2}\left(5 \times 5 \mu \mathrm{m}^{2}\right)$, b) polystyrene treated $\mathrm{SiO}_{2}\left(5 \times 5 \mu \mathrm{m}^{2}\right)$ and c) polystyrene treated $\mathrm{SiO}_{2}\left(1 \times 1 \mu^{2}\right)$. AFM images of vacuum-deposited 4 films deposited on d) bare $\mathrm{SiO}_{2}\left(5 \times 5 \mu \mathrm{m}^{2}\right)$ and e) polystyrene treated $\mathrm{SiO}_{2}\left(5 \times 5 \mu \mathrm{m}^{2}\right)$. 
width of $600 \mathrm{~nm}$ and lengths that include from $600-1400 \mathrm{~nm}$. Only an slight enhancement of the interconnectivity between the grains is observed for films based on $\mathbf{3}$ deposited on PS-treated 5 surfaces, which actually correspond to a higher device performance (Fig. 6a and b, Table 1). Vacuum-deposited 3 films presented a terrace-like step morphology (Fig. 6c), independent of the modification of the dielectric surface.

Vacuum-deposited 4 films on bare and on PS-treated $\mathrm{SiO}_{2}$ also 10 presented identical morphologies, independently of the modification of the dielectric surface (Fig. 6d and e). AFM images exhibited protrusions/hillocks, whose average thickness was in the order of $130 \mathrm{~nm}$ and their height varied from $50 \mathrm{~nm}$ to more than $100 \mathrm{~nm}$.

15 Combining GIXRD and AFM data, it can be established that vacuum deposited films of indolocarbazole $\mathbf{3}$ and triindole $\mathbf{4}$ derivatives on bare and on PS-treated $\mathrm{SiO}_{2}$ surfaces, respectively, presented identical X-ray diffraction patterns and morphology. Therefore, the addition of a polystyrene SAM has a null influence 20 on the growth of the molecular order and on the morphology of the thin film. The improvement of the electrical characteristics of the OTFT devices observed in PS-treated $\mathrm{c}-\mathrm{Si} / \mathrm{SiO}_{2}$ substrates appears to be related to the improvement of the interface contact between the dielectric and the semiconductor layer.

\section{${ }_{25}$ Experimental section}

\section{Materials}

All reagents for syntheses were obtained from commercial sources and were used as received without further purification. Indolo[3,2-b]carbazole was synthesized according to previously 30 reported method. ${ }^{10}$ Triazatruxene was synthesized according to a previously reported method. ${ }^{11}$

\section{Synthesis of 9,9'-dimethyl-9H,9H'-[3,3']bicarbazole (2)}

9-methyl-9H-carbazole 1 (5.6 g, $31.1 \mathrm{mmol}$ ) was dissolved in 35 anhydrous $\mathrm{CHCl}_{3}(70 \mathrm{~mL})$ under inert atmosphere. Subsequently, $\mathrm{FeCl}_{3}(13.7 \mathrm{~g}, 84.5 \mathrm{mmol})$ was added and the reaction mixture was stirred at room temperature for 30 minutes. Then, the mixture was poured into methanol and the formation of a precipitate was observed. The solid was isolated by vacuum filtration, washed 40 thoroughly with methanol and then dried. The crude was purified by flash column chromatography using a mixture of hexane and $\mathrm{CH}_{2} \mathrm{Cl}_{2}(1: 1 \mathrm{v} / \mathrm{v})$ as eluent to give compound 2 (4.3 g, 73\%). ${ }^{1} \mathrm{H}$ NMR (400 MHz, $d_{6}$-DMSO), $\delta: 8.55$ (d, $J=1.7 \mathrm{~Hz}, 2 \mathrm{H}$ ), 8.26 (d, $J=7.6 \mathrm{~Hz}, 2 \mathrm{H}$ ), 7.89 (dd, $J=8.5 \mathrm{~Hz}, J=1.7 \mathrm{~Hz}, 2 \mathrm{H}$ ), 7.67 (d, $J$ $\left.{ }_{45}=8.5 \mathrm{~Hz}, 2 \mathrm{H}\right), 7.58$ (d, $\left.J=8.2 \mathrm{~Hz}, 2 \mathrm{H}\right), 7.50-7.46$ (m, 2H), 7.247.21 (m, 2H), 3.92 (s, 6H, N-CH $)$ ppm. ${ }^{13} \mathrm{C}$ NMR (100 MHz, $d_{6^{-}}$ DMSO), $\delta$ : 141.1, 139.7, 132.2, 125.8, 125.0, 122.7, 122.3, 120.4, 118.7, 118.2, 109.4, 109.2, 29.1 ppm. HRMS (ESI-MS) $(\mathrm{m} / \mathrm{z})$ : calcd for $\mathrm{C}_{26} \mathrm{H}_{21} \mathrm{~N}_{2}(\mathrm{M}+\mathrm{H})^{+}$361.1699, found: 361.1684.

\section{Synthesis of 5,11-dimethylindolo[3,2-b]carbazole (3)}

$\mathrm{NaH}$ (12 mg, $0.52 \mathrm{mmol}$ ) was added to a solution of indolo[3,2$b$ carbazole (60 $\mathrm{mg}, 0.23 \mathrm{mmol}$ ) in anhydrous DMF under an inert atmosphere. The solution was stirred at room temperature 55 for 30 minutes. Then, methyl iodide ( $32 \mu \mathrm{L}, 0.52 \mathrm{mmol}$ ) was added and the mixture was stirred at room temperature for 30 minutes and then treated with $\mathrm{H}_{2} \mathrm{O}$. The aqueous layer was extracted with dichloromethane and the organic layer was dried over $\mathrm{Na}_{2} \mathrm{SO}_{4}$. The solvent was removed by evaporation and the 60 crude was purified by flash column chromatography using a mixture of hexane and dichloromethane $(4: 1 \mathrm{v} / \mathrm{v})$ to give compound 3 (55 mg, 83\%). ${ }^{1} \mathrm{H}$ NMR (400 MHz, $\mathrm{CDCl}_{3}$ ), $\delta: 8.20$ (d, $J=8.0 \mathrm{~Hz}, 2 \mathrm{H}), 8.02$ (s, 2H), 7.53-7.49 (m, 2H), 7.42 (d, $J=$ $8.0 \mathrm{~Hz}, 2 \mathrm{H}), 7.26-7.22$ (m, 2H), 3.96 (s, 6H, N-CH $)^{\mathrm{ppm} .}{ }^{13} \mathrm{C}$ 65 NMR (100 MHz, $\mathrm{CDCl}_{3}$ ), $\delta=142.3,136.9,125.8,123.0,122.9$, 120.3, 118.2, 108.3, 98.7, 29.5 ppm. HRMS (ESI-MS) $(\mathrm{m} / \mathrm{z})$ : calcd for $\mathrm{C}_{20} \mathrm{H}_{17} \mathrm{~N}_{2}(\mathrm{M}+\mathrm{H})^{+}$285.1386, found: 285.1382.

\section{Synthesis of $\mathrm{N}$-trimethyltriindole (4)}

$70 \mathrm{NaH}$ (98 mg, $4.05 \mathrm{mmol}$ ) was added to a solution of triazatruxene (0.28 g, $0.81 \mathrm{mmol})$ in anhydrous DMF under inert atmosphere. The solution was stirred at room temperature for 30 minutes. Then, methyl iodide (166 $\mu \mathrm{L}, 2.67 \mathrm{mmol})$ was added and the mixture was stirred at room temperature for 30 minutes and then 75 treated with $\mathrm{H}_{2} \mathrm{O}$. The aqueous layer was extracted with dichloromethane and the organic layer was dried over $\mathrm{Na}_{2} \mathrm{SO}_{4}$. The solvent was removed by evaporation and the crude was purified by flash column chromatography using a mixture of hexane and dichloromethane $(5: 1 \mathrm{v} / \mathrm{v})$ as eluent to give 80 compound 4 (0.26 g, 84\%). ${ }^{1} \mathrm{H}$ NMR (400 MHz, $\mathrm{CDCl}_{3}$ ), $\delta: 8.47$ (d, $J=8.0 \mathrm{~Hz}, 3 \mathrm{H}), 7.59$ (d, $J=8.0 \mathrm{~Hz}, 3 \mathrm{H}), 7.49-7.45$ (m, 3H), 7.37-7.33 (m, 3H), 4.48 (s, 9H, N-CH $)_{3}$ ppm. ${ }^{13} \mathrm{C}$ NMR (100 $\mathrm{MHz}, \mathrm{CDCl}_{3}$ ), $\delta=142.1,139.2,123.0$ (2C), 121.9, 120.0, 109.8, 102.7, $36.1 \mathrm{ppm}$. HRMS (ESI-MS) $(\mathrm{m} / \mathrm{z})$ : calcd for $\mathrm{C}_{27} \mathrm{H}_{22} \mathrm{~N}_{3}$ ${ }_{85}(\mathrm{M}+\mathrm{H})^{+} 388.1808$, found: 388.1810.

\section{Instrumentation and methods}

Flash column chromatography was carried out over silica gel (SDS, 230-240 mesh). ${ }^{1} \mathrm{H}$ NMR (400 MHz) and ${ }^{13} \mathrm{C}$ NMR (100 ${ }_{90} \mathrm{MHz}$ ) spectra were collected on a Varian Mercury spectrophotometer. NMR spectra have been processed with the MestRec Nova software. HRMS was performed in a LC/MSDTOF Agilent Technologies apparatus by means of the electrospray (ESI-MS) technique. UV-Vis spectra were registered 95 using a Varian Cary UV-Vis-NIR 500E spectrophotometer. TGA were performed with a Mettler Toledo TGA/SDTA 851e instrument at a heating rate of $10 \mathrm{~K} \mathrm{~min}^{-1}$. Differential scanning calorimetry (DSC) thermograms were recorded using a MettlerToledo DSC821 module under nitrogen flow. Cyclic 100 voltammograms were carried out using a microcomputercontrolled potentiostat/galvanostat Autolab with PGSTAT30 equipment and GPES software. A cylindrical three-electrode cell was used. The reference electrode was a Metrohm $\mathrm{Ag} / \mathrm{AgCl} / \mathrm{KCl}$ (3M) mounted in a Luggin capillary containing a $0.1 \mathrm{M}$ solution 105 of tetrabutylammonium perchlorate (TBAP) in dichloromethane.

The counter and working electrodes were a platinum spiral and a platinum wire, respectively. All voltammetric curves were recorded under quiescent conditions, at a scan rate of $100 \mathrm{mV} \mathrm{s}^{-1}$ and under argon atmosphere. All solutions were prepared in 110 dichloromethane $(1 \mathrm{mM})$. Tetrabutylammonium perchlorate (Aldrich, electrochemical grade) was used as a supporting electrolyte. The energy of the HOMO level was estimated from 
the onset of the first oxidation peak as $E_{\mathrm{HOMO}}=-E_{\text {onset }}{ }^{\text {ox }}+$ $E^{0}\left(\mathrm{Fc} / \mathrm{Fc}^{+}\right)-5.39$, where $E^{0}\left(\mathrm{Fc} / \mathrm{Fc}^{+}\right)=+0.19 \mathrm{~V} v \mathrm{~s}$. $\mathrm{Ag} / \mathrm{AgCl} / \mathrm{KCl}$ (3M), and where $-5.39 \mathrm{eV}$ corresponds to the formal potential of the $\mathrm{Fc}^{+} / \mathrm{Fc}$ redox couple in the Fermi scale. ${ }^{16}$ The energy of the ${ }_{5}$ LUMO level was calculated as $E_{\mathrm{LUMO}}=E_{\mathrm{HOMO}}+E_{\text {gap }}$. Singlecrystal analysis of material $\mathbf{3}$ was performed on a D8 Venture system equipped with a multilayer monochromator and a Mo high brilliance Incoatec Microfocus Source $(\lambda=0.71073 \AA)$. The frames were integrated with the Bruker SAINT software package 10 using a narrow-frame algorithm. The structure was solved and refined using the Bruker SHELXTL Software Package. Powder $\mathrm{X}$-ray diffraction (XRD) measurements were obtained by using a PANalytical X'Pert PRO MPD $\theta / \theta$ powder diffractometer, in a configuration of convergent beam with a focalizing mirror and 15 transmission geometry with a spinner glass capillary sample holder, a PIXcel detector and with $\mathrm{Cu} \mathrm{K} \alpha$ radiation at $45 \mathrm{kV}$ and $40 \mathrm{~mA}$. Samples were prepared by introduction of powder materials $\mathbf{3}$ and $\mathbf{4}$ in Lindemann glass capillaries of 0.5 millimetres of diameter. Grazing incidence XRD (GIXRD) 20 measurements of the thin-films of the sublimated organic materials were performed in a PANalytical X'Pert PRO MRD diffractometer with a PIXcel detector, a parabolic Göbel mirror at the incident beam and a parallel plate collimator at the diffracted beam, and with $\mathrm{Cu} \mathrm{K \alpha}$ radiation at $45 \mathrm{kV}$ and $40 \mathrm{~mA}$. The angle 25 of incidence used was $\omega=0.17^{\circ}$. Thin films $(75 \mathrm{~nm})$ were prepared from compounds $\mathbf{3}$ and $\mathbf{4}$ by sublimation on a vacuum system on a c-Si/ $\mathrm{SiO}_{2}$ substrate and on polystyrene-treated c$\mathrm{Si} / \mathrm{SiO}_{2}$ substrates with the deposition rate at $0.3 \AA \mathrm{s}^{-1}$ under a pressure below $10^{-6}$ mbar. AFM experiments were conducted 30 using a AFM Dimension 3100 system attached to a Nanoscope IVa electronics unit (Bruker).

\section{OTFT device fabrication}

OTFTs devices were fabricated using the bottom-gate top-contact 35 geometry. The substrate consisted in a thermally oxidized crystalline silicon wafer that provided a gate dielectric $\left(\mathrm{SiO}_{2}\right)$ of thickness $50 \mathrm{~nm}$ and $110 \mathrm{~nm}$. Polystyrene (PS) was used as a selfassembled monolayer to improve the device performance. A solution of PS in toluene ( $4 \mathrm{mg} \mathrm{mL}^{-1}$ ) was deposited drop wise on 40 the substrate. The substrate was spun at $500 \mathrm{rpm}$ for $5 \mathrm{~s}$ and 2500 rpm for $30 \mathrm{~s}$ with a P6700 spin coater. Organic materials 2-4 were deposited by sublimation in a vacuum system with base pressure below $10^{-6}$ mbar. The sublimation temperature for the organic compounds was regulated from 152 to $160^{\circ} \mathrm{C}, 120$ to

${ }_{45} 130^{\circ} \mathrm{C}$ and 160 to $170^{\circ} \mathrm{C}$, respectively, to maintain a stable deposition rate around $0.3 \AA \mathrm{s}^{-1}$ to obtain a $75 \mathrm{~nm}$ thickness layer. Then, they were transferred to a different vacuum chamber used to evaporate the metallic contacts. Gold was used for source and drain electrodes, which were defined using a metallic mask that 50 defines a channel length (L) and width (W) of $80 \mu \mathrm{m}$ and $2 \mathrm{~mm}$, respectively. The fabricated OTFTs were electrically characterized in dark and under air conditions. The electrical characteristics were measured using an Agilent 4156C parameter analyser.

\section{${ }_{55}$ Conclusions}

All the carbazole-based compounds 1-4 presented low HOMO levels and high HOMO-LUMO gaps, indicating their potential hole transporting properties and air-stability. However, only compounds $\mathbf{3}$ and $\mathbf{4}$, with extended $\pi$-conjugated cores with two 60 and three fused carbazole rings, presented good device performances and air-stability and durability under air conditions, for longer periods up to 5 months, with hole mobility values ranging from $10^{-3}$ to $10^{-2} \mathrm{~cm}^{2} \mathrm{~V}^{-1} \mathrm{~s}^{-1}$. For indolocarbazole derivative 3 , a herringbone packing motif with $\mathrm{CH}_{3} \cdots \pi$ 65 interactions has been described in the semiconductor layer, whereas a cofacial molecular packing is observed for triindole 4 . For the latter, it has been found that in the crystal structure and in the thin film, presents a face-to-face molecular packing, and exhibits the best OTFT performance. For this material, an optimal 70 perpendicular molecular disposition to the substrate surface was determined by GIXRD. Indolo[3,2-b]carbazole and specially triindole units are shown to be promising $\pi$-conjugated cores for new organic semiconductors for electronic devices.

\section{Notes and references}

${ }_{75}{ }^{a}$ Grup de Materials Orgànics, Institut de Nanociència i Nanotecnologia (IN $\left.{ }^{2} U B\right)$, Departament de Química Orgànica, Universitat de Barcelona, Martí i Franquès 1, E-08028, Barcelona, Spain. Fax: +34 9333978 78; Tel: +349340392 60; E-mail: dvelasco@ub.edu

${ }^{b}$ Dept. Eng. Electrònica \& Centre de Recerca en Nanoenginyeria,

80 Universitat Politècnica de Catalunya, C/ Jordi Girona, 1-3, 08034, Barcelona, Spain. Tel: +34 9340110 02; E-mail:

joaquim.puigdollers@upc.edu

† Electronic Supplementary Information (ESI) available: [Absorption spectra, cyclic voltammograms, OTFTs characteristics, detailed 85 crystallographic data and powder X-ray diffraction patterns]. See DOI: $10.1039 / \mathrm{b} 000000 \mathrm{x} /$

1 a) R. Fitzner, E. Mena-Osteritz, A. Mishra, G. Schulz, E. Reinold, M. Weil, C. Körner, H. Ziehlke, C. Elschner, K. Leo, M. Riede, M. Pfeiffer, C. Uhrich, P. Bäuerle, J. Am. Chem. Soc., 2012, 134, 11064.

90 b) J. Mei, Y. Diao, A. L. Appleton, L. Fang, Z. Bao, J. Am. Chem. Soc., 2013, 135, 6724.

2 a) M. E. Roberts, S. C. B. Mannsfeld, N. Queraltó, C. Reese, J. Locklin, W. Knoll, Z. Bao, PNAS, 2008, 105(34), 12134. b) H. Klauk, M. Halik, U. Zschieschang, G. Schmid, W. Radlik, W. Weber, J. Appl. Phys., 2002, 92, 5259.

3 a) D. Simeone, S. Cipolloni, L. Mariucci, M. Rapisarda, A. Minotti, A. Pecora, M. Cuscunà, L. Maiolo, G. Fortunato, Thin Solid Films, 2009, 517, 6283.b) K. Takimiya, T. Yamamoto, H. Ebata, T. Izawa, Science and Technology of Advanced Materials, 2007, 8, 273.

1004 a) S. Castellanos, V. Gaidelis, V. Jankauskas, J. Grazulevicius, E. Brillas, F. López-Calahorra, L. Juliá, D. Velasco, Chem. Commun., 2010, 46, 5130. b) A. Tomkeviciene, J. V. Grazulevicius, D. Volyniuk, V. Jankauskas, G. Sini, Phys. Chem. Chem. Phys, 2014, 16, 13932. c) Y. M. Tao, H. Y. Li, Q. L. Xu, Y. C. Zhu, L. C. Kang, 105 Y. X. Zheng, J.-L. Zuo, X. Z. You, Synth. Met., 2011, 161, 718. d) P. Sigwalt, G. Wegner, J.-F. Morin, M. Leclerc, D. Adès, A. Siove, Macromol. Rapid. Commun., 2005, 26, 761.

5 a) H. Zhao, L. Jiang, H. Dong, H. Li, W. Hu, B. S. Ong. Chem. Phys. Chem., 2009, 10, 2345. b) P.-L. T. Boudreault, S. Wakim, M. L.

110 Tang, Y. Tao, Z. Bao, M. Leclerc, J. Mater. Chem., 2009, 19, 2921.

6 a) X. Qian, Y.-Z. Zhu, J. Song, X.-P. Gao, J.-Y. Zheng, Org. Lett., 2013, 15(23), 6034. b) S. W. Shelton, T. L. Chen, D. E. Barclay, B. Ma, Appl. Mater. Interfaces, 2012, 4, 2534.

7 a) D. H. Huh, G. W. Kim, G. H. Kim, C. Kulshreshta, J. H. Kwon, 115 Synthetic Metals, 2013, 180, 79. b) W. Y. Lai, Q. Y. He, R. Zhu, Q. Q. Chen, W. Huang, Adv. Funct. Mater., 2008, 18, 265.

8 E. M. García-Frutos, U. K. Pandey, R. Termine, A. Omenat, J. Barberá, J. L. Serrano, A. Golemme, B. Gómez-Lor, Angew. Chem. Int. Ed., 2011, 50, 7399.

1209 a) V. Vaitkeviciene, S. Grigalevicius, J. V. Grazulevicius, V. Jankauskas, V. G. Syromyatnikov, European Polymer Journal, 2006, 
42, 2254. b) T. Tokuda, K. Murashiro, M. Kubo, H. Masu, M. Imanari, H. Seki, N. Aoki, Y. Ochiai, H. Kanoh, K. Hoshino, Langmuir, 2012, 28, 16430.

10 B. Robinson, J. Chem. Soc., 1963, 3097.

511 a) M. Franceschin, L. Ginnari-Satriani, A. Alvino, G. Ortaggi, A. Bianco, Eur. J. Org. Chem., 2010, 1, 134. b) L. Ji, Q. Fang, M.-S. Yuan, Z.-Q. Liu, Y.-X. Shen, H.-F. Chen, Org. Lett., 2010, 12(22), 5192.

12 E. M. García-Frutos, E. Gutierrez-Puebla, M. A. Monge, R. Ramírez,

10 P. de Andrés, A. de Andrés, R. Ramírez, B. Gómez-Lor, Organic Electronics, 2009, 10, 643.

13 G. Zhao, H. Dong, H. Zhao, L. Jiang, X. Zhang, J. Tan, Q. Meng, W. Hu, J. Mater. Chem., 2012, 22, 4409.

14 S. Wakim, J. Bouchard, M. Simard, N. Drolet, Y. Tao, M. Leclerc, 15 Chem. Mater., 2004, 16, 4386.

15 P.-L. T. Boudreault, S. Wakim, N. Blouin, M. Simard, C. Tessier, Y. Tao, M. Leclerc. J. Am. Chem. Soc., 2007, 129, 9125.

16 a) C. M. Cardona, W. Li, A. E. Kaifer, D. Stockdale, G. C. Bazan, Adv. Mater., 2011, 23, 2367. b) A. J. Bard, L. R. Faulkner,

20 Electrochemical Methods: Fundamentals and Applications, WILEYVCH, New York, 2001.

\section{Acknowledgements}

Financial support from the Ministerio de Economía y Competitividad (CTQ2012-36074 and TEC2011-27859) is 25 gratefully acknowledged. M. Reig grates for the grant ADR from Universitat de Barcelona (UB). We also thank Xavier Alcobé and Josep $\mathrm{M}^{\mathrm{a}}$ Bassas from the X-ray diffraction unit of the Scientific and Technological Centers of the University of Barcelona (CCiTUB) for the realization of the X-ray diffraction 30 measurements and their helpful discussion. 